Document downloaded from:

http://hdl.handle.net/10251/101918

This paper must be cited as:

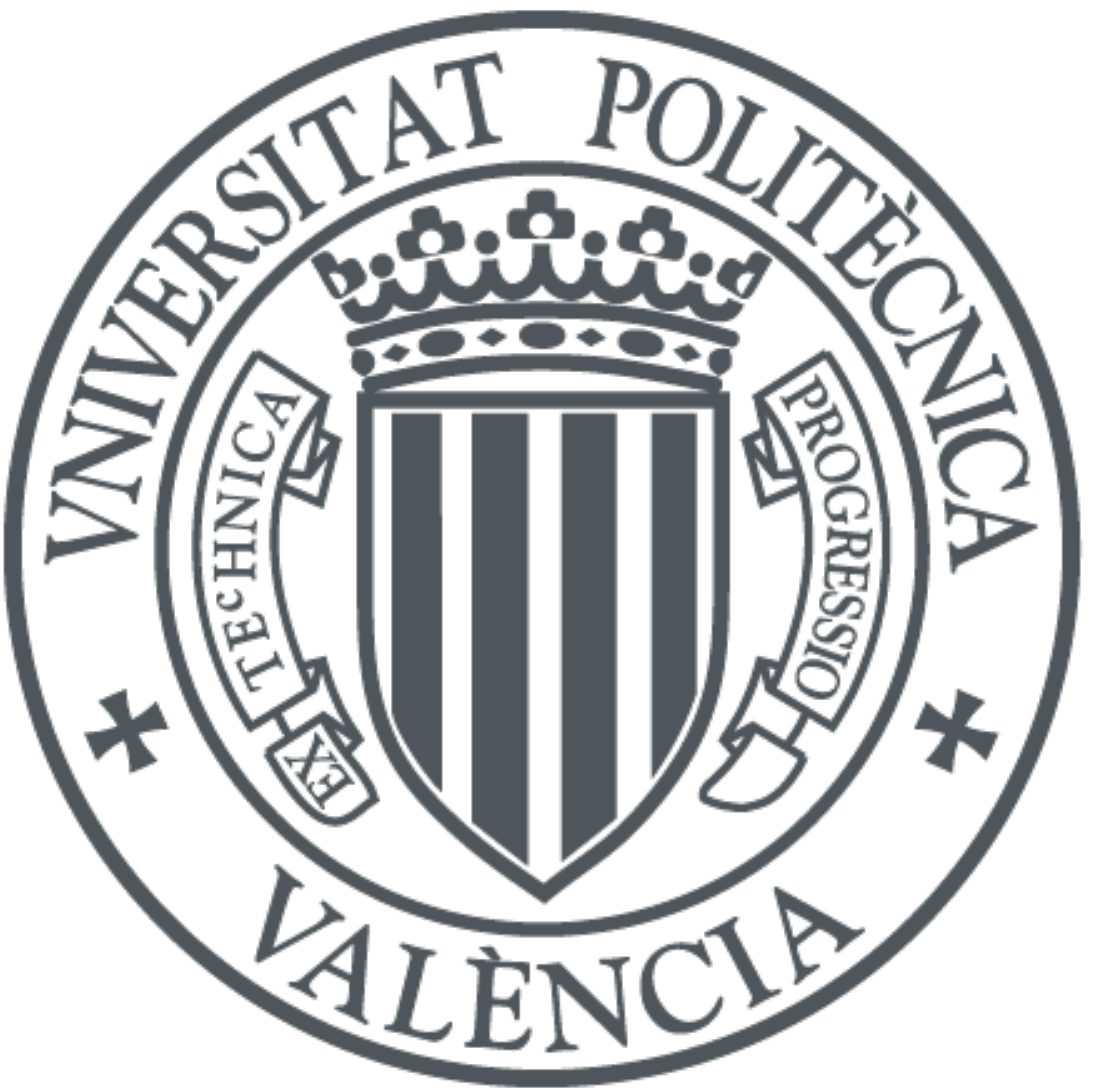

The final publication is available at

http://doi.org/10.1016/j.spmi.2017.04.007

Copyright Elsevier

Additional Information 


\title{
Analysis of the power conversion efficiency of perovskite solar cells with different materials as Hole-Transport Layer by numerical simulations
}

\author{
G.A. Casas ${ }^{1,2}$, M.A. Cappelletti ${ }^{1,3,5}$, A.P. Cédola ${ }^{1,6}$, Bernabé Marí Soucase ${ }^{4}$ y E.L. Peltzer y \\ Blancá $^{1,5}$ \\ ${ }^{1}$ Grupo de Estudio de Materiales y Dispositivos Electrónicos (GEMyDE), \\ Facultad de Ingeniería, Universidad Nacional de La Plata, 48 y 116, CC. 91, La Plata (1900), \\ Buenos Aires, Argentina, Tel. 0221-4236690 \\ ${ }^{2}$ Universidad Nacional de Quilmes, Roque Saenz Peña 352, \\ Bernal (1876), Buenos Aires, Argentina \\ ${ }^{3}$ Universidad Nacional Arturo Jauretche, Avenida Calchaquí 6200, \\ Florencio Varela (1888), Buenos Aires, Argentina \\ ${ }^{4}$ Department de Física Aplicada-ETSED, Universitat Politècnica de València, Camí de Vera \\ s/n, 46022 València, Spain \\ 5 Comisión Nacional de Investigaciones Científicas (CONICET), Argentina \\ ${ }^{6}$ Comisión de Investigaciones Científicas, Provincia de Buenos Aires (CIC), Argentina
}

E-mail: guillecasas1958@gmail.com

\begin{abstract}
In this paper, a theoretical study of different p-p-n perovskite solar cells has been performed by means of computer simulation. Effects of the offset level upon the power conversion efficiency $(P C E)$ of these devices have been researched using five different materials such as spiro-OMeTAD, $\mathrm{Cu}_{2} \mathrm{O}, \mathrm{CuSCN}, \mathrm{NiO}$ and CuI, as Hole Transporting Layer (HTL). The Solar Cells Capacitance Simulator (SCAPS)-1D has been the tool used for numerical simulation of these devices. A strong dependence of $P C E$ has been found with the difference between the Maximum of the Valence Band of the HTL and perovskite materials, and with the doping level in p-type perovskite layer. A minimum value of hole mobility in the HTL has been also found, below which the PCE is reduced. Efficiencies in the order of $28 \%$ have been obtained for the $\mathrm{Cu}_{2} \mathrm{O} /$ Perovskite/TiO ${ }_{2}$ solar cell. Results obtained in this work show the potentiality of this promising technology.
\end{abstract}

Keywords: Solar energy; Perovskite; Hole Transporting Layer (HTL); Numerical simulation

\section{Introduction}

In the last few years, the perovskite solar cells have had a significant increase in performance, which has strongly encouraged many experimental and theoretical studies in order to optimize the design of the structure and the selection of materials. These works are aimed at improving the performance of a technology that promises to achieve high power conversion efficiencies $(P C E)$ at low cost. In particular, the development and progress of the perovskite solar cells, regarding efficiency, stability, cost and commercialization, have been discussed in detail in previous publications $[1,2]$. Perovskite solar cells represent an emerging photovoltaic technology, for which efficiencies have been increased substantially from 3.8\% in 2009 [3] to $22.1 \%$ recently [4], confirming the upward trend of this promising technology. 
Figure 1 shows the planar structure of perovskite solar cells, where it can be seen that the light is absorbed by the intermediate region called perovskite layer, whereas the holetransporting layer (HTL) and the electron-transporting layer (ETL) link the carrier generation region with the electrodes. For the purpose of an efficient carrier collection in the electrodes, the ETL must block the flow of holes but allow the free electrons flow towards the cathode. On the contrary, the HTL must block the flow of electron but allow the free flow of holes towards the anode, as shown in Figure 1. The effects of variations in the characteristics of the perovskite layer and of the interfaces with the other two layers have been investigated recently through modeling and simulation techniques [5-8]. In another works, a comparative study using two different transparent conducting oxides such as $\mathrm{TiO}_{2}$ and $\mathrm{ZnO}$ as electron transporting materials have been recently researched [9, 10]. The ETL, HTL and the perovskite layers are the path that photogenerated carriers must travel before being collected. A good understanding of the effects of each of the layers in the performance of the devices is critical for optimization. The most common material used for the HTL layer is spiro$\operatorname{OMeTAD}\left(2,2^{\prime}, 7,7^{\prime}\right.$-tetrakis (N,N-di-p-methoxyphenylamine)-9,9'-spirobifluorene), which is relatively expensive. In this work, a comparative study of the effects of replacing this organic compound with four different inorganic materials such as $\mathrm{Cu}_{2} \mathrm{O}, \mathrm{CuSCN}, \mathrm{NiO}$ and $\mathrm{CuI}$ has been carried out by means of computer simulation. These semiconductor materials have different band gap energies $(E g)$ and electron affinities (Xe), which lead to different alignments between the valence bands of both the HTL and the perovskite layer. All inorganic compounds under consideration in this study are promising candidate for hole transporting material and electron blocking layer $[11,12]$. The authors have previously used numerical simulations in order to study the behavior of solar cells and PIN photodiodes under different operating conditions [10, 13-15].

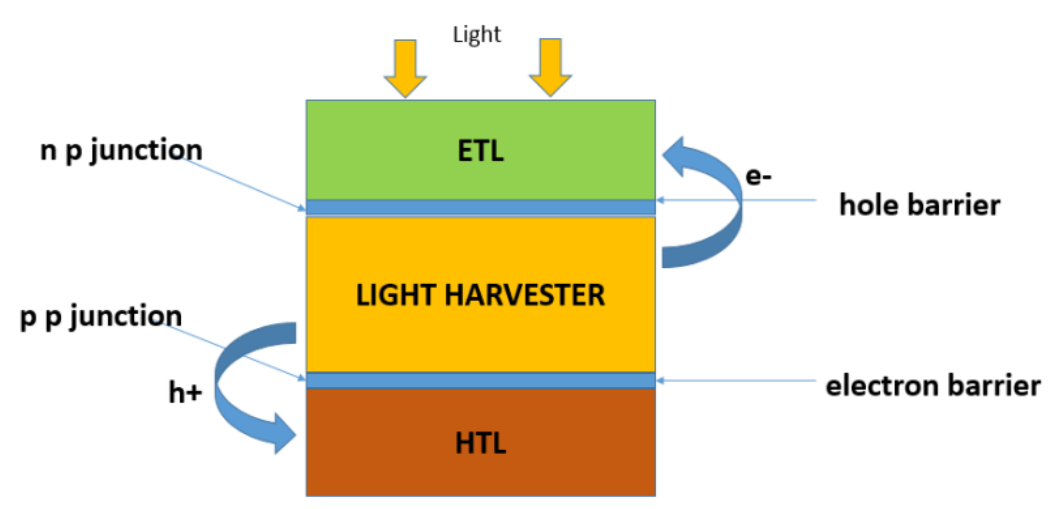

Figure 1. The planar structure of a perovskite solar cell. 
Figure 2 illustrates typical values of energy in electron volts $(\mathrm{eV})$ of the Minimum of the Conduction Band (MCB) and of the Maximum of the Valence Band (MVB), with respect to the vacuum energy level, for the alternative HTL materials spiro-OMeTAD, CuI, NiO, $\mathrm{CuSCN}$, and $\mathrm{Cu}_{2} \mathrm{O}$, for the perovskite $\mathrm{CH}_{3} \mathrm{NH}_{3} \mathrm{PbI}_{3}$ and for $\mathrm{TiO}_{2}$ used as ETL region. The subtraction between these two values is $E g$, whereas the subtraction between the MCB and the vacuum energy level gives $X_{\mathrm{e}}$. Also, the offset level is referred as the difference between the MVB of the HTL and perovskite materials (Offset $\left.=M V B_{H T L}-M V B_{\text {Perovskite }}\right)$.

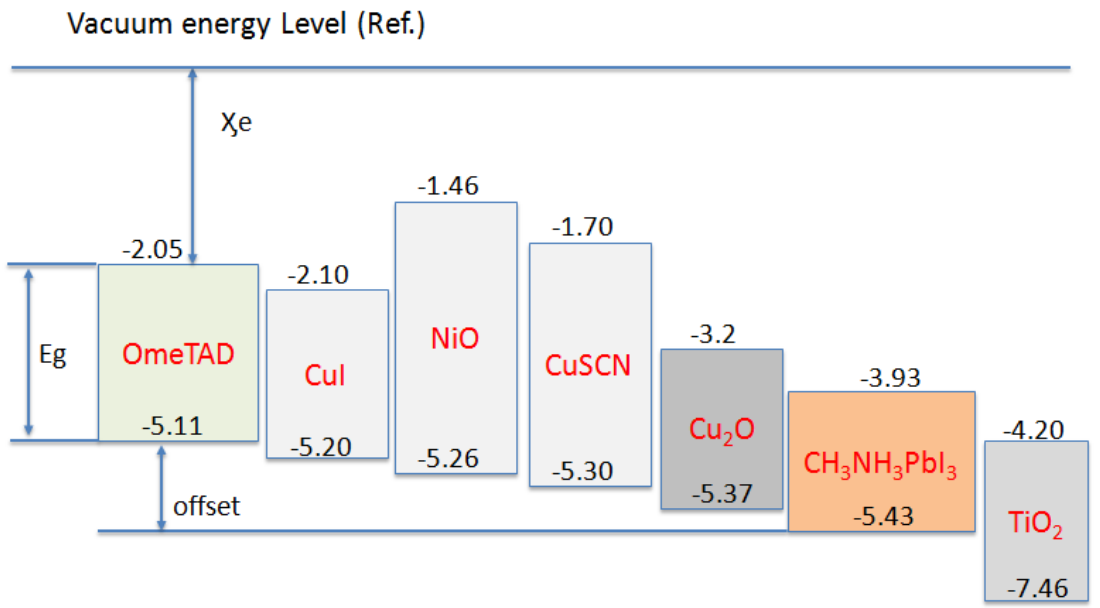

Figure 2. Values of (eV) of the Minimum of the Conduction Band (on the top) and of the Maximum of the Valence Band (on the bottom), with respect to the vacuum energy level, for all materials considered in this work.

\section{Simulation Details}

Numerical simulations of p-p-n perovskite solar cells exploiting the planar structure shown in Figure 1 were performed with the one-dimensional code SCAPS-1D (Solar Cells Capacitance Simulator) [16]. This simulation program solves numerically the three basic semiconductor equations: the Poisson and the continuity equations for holes and for electrons. It has been applied to the numerical simulation of perovskite solar cells recently [7, 10].

In this work, the heterojunction solar cells are simulated with three input layers, where p-type spiro-OMeTAD, $\mathrm{Cu}_{2} \mathrm{O}, \mathrm{CuSCN}, \mathrm{NiO}$ and $\mathrm{CuI}$ are used separately in order to compare their performance as HTL, low p-type doped perovskite $\left(\mathrm{CH}_{3} \mathrm{NH}_{3} \mathrm{PbI}_{3}\right)$ is used as active layer, and n-type transparent conducting oxide $\mathrm{TiO}_{2}$ is used as ETL. It is considered that solar energy is entered through the ETL layer. The standard AM1.5G spectrum $\left(1000 \mathrm{~W} / \mathrm{m}^{2} ; \mathrm{T}=300^{\circ} \mathrm{K}\right)$ has been used.

Table 1 summarizes the physical parameters used for each layer in the numerical analysis, where $N_{C}$ and $N_{V}$ are the effective density of states (DOS) in the conduction and the valence bands, respectively; $\mu_{\mathrm{n}}$ and $\mu_{\mathrm{p}}$ are the electron and hole mobilities, respectively; $\varepsilon$ is the relative permittivity; and $N_{A}$ and $N_{D}$ are the acceptor and donor impurity concentrations, 
respectively. These values were extracted either from literature $[6,7,10,17-23]$ or estimated as in the case of $N_{C}, N_{V}, N_{A}$ and $N_{D}$ for the inorganic HTL materials. Specifically, $N_{C}, N_{V}, N_{A}$ and $N_{D}$ for spiro-OMeTAD were extracted from literature $[6,10]$. These values are a good first-approximation for each inorganic material considered in this work. Anyway, to verify the validity of these parameters, theoretical values of $N_{C}$ and $N_{V}$ for the $\mathrm{Cu}_{2} \mathrm{O}$ calculated by ab initio techniques [24] have been used in the simulations and no differences were found. Additionally, no changes were found in the results when simulations for $\mathrm{Cu}_{2} \mathrm{O}, \mathrm{CuSCN}, \mathrm{NiO}$ and CuI, with $N_{C}, N_{V}$ in the range from $2.50 \times 10^{18}$ to $2.50 \times 10^{21}$ and $N_{A}$ in the range from $3.0 \times 10^{16}$ to $3.0 \times 10^{19}$ have been performed.

Typical thicknesses of each layer were fixed. In particular, $400 \mathrm{~nm}$ thick perovskite film ensures a radiation absorption close to the maximum, without major recombination losses [6, 10]. Values extracted from literature were used for the absorption coefficients of $\mathrm{TiO}_{2}$ [25], perovskite and spiro-OMeTAD [26], $\mathrm{Cu}_{2} \mathrm{O}$ [27], $\mathrm{CuSCN}$ [28] and $\mathrm{NiO}$ [29]. The absorption coefficient of $\mathrm{CuI}$ is considered constant and equal to $1.00 \times 10^{5} \mathrm{~cm}^{-1}$ up to the wavelength corresponding to the band gap of this material.

Table 1. Physical parameters used in the numerical analysis for each layer.

\begin{tabular}{|c|c|c|c|c|c|c|}
\hline & & $\mathrm{Cu}_{2} \mathrm{O}$ & $\mathrm{CuSCN}$ & $\mathrm{NiO}$ & $\mathrm{CuI}$ & spiro-OMeTAD \\
\hline \multirow{10}{*}{$\begin{array}{l}\text { HTL } \\
(400 \mathrm{~nm})\end{array}$} & $E_{\mathrm{g}}(\mathrm{eV})$ & 2.17 & 3.6 & 3.8 & 3.1 & 3.06 \\
\hline & $X_{\mathrm{e}}(\mathrm{eV})$ & 3.2 & 1.7 & 1.46 & 2.1 & 2.05 \\
\hline & $N_{\mathrm{C}}\left(\mathrm{cm}^{-3}\right)$ & $2.50 \times 10^{20}$ & $2.50 \times 10^{20}$ & $2.50 \times 10^{20}$ & $2.50 \times 10^{20}$ & $2.50 \times 10^{20}$ \\
\hline & $N_{\mathbf{v}}\left(\mathrm{cm}^{-3}\right)$ & $2.50 \times 10^{20}$ & $2.50 \times 10^{20}$ & $2.50 \times 10^{20}$ & $2.50 \times 10^{20}$ & $2.50 \times 10^{20}$ \\
\hline & $\mu_{\mathrm{n}}\left(\mathrm{cm}^{2} \mathrm{~V}^{-1} \mathrm{~s}^{-1}\right)$ & 80 & 25 & 2.8 & 44 & $2.00 \times 10^{-4}$ \\
\hline & $\mu_{\mathrm{p}}\left(\mathrm{cm}^{2} \mathrm{~V}^{-1} \mathrm{~s}^{-1}\right)$ & 80 & 25 & 2.8 & 44 & $2.00 \times 10^{-4}$ \\
\hline & $\varepsilon$ & 6.6 & 5.1 & 11.7 & 6.5 & 3.0 \\
\hline & $N_{\mathrm{A}}\left(\mathrm{cm}^{-3}\right)$ & $3.00 \times 10^{18}$ & $3.00 \times 10^{18}$ & $3.00 \times 10^{18}$ & $3.00 \times 10^{18}$ & $3.00 \times 10^{18}$ \\
\hline & $N_{\mathbf{D}}\left(\mathrm{cm}^{-3}\right)$ & 0 & 0 & 0 & 0 & 0 \\
\hline & Offset (eV) & 0.06 & 0.13 & 0.17 & 0.23 & 0.32 \\
\hline \multirow{9}{*}{$\begin{array}{l}\text { Perovskite } \\
(400 \mathrm{~nm})\end{array}$} & $E_{\mathrm{g}}(\mathrm{eV})$ & 1.5 & & & & \\
\hline & $X_{\mathrm{e}}(\mathrm{eV})$ & 3.93 & & & & \\
\hline & $N_{\mathrm{C}}\left(\mathrm{cm}^{-3}\right)$ & $2.50 \times 10^{20}$ & & & & \\
\hline & $N_{\mathbf{v}}\left(\mathrm{cm}^{-3}\right)$ & $2.50 \times 10^{20}$ & & & & \\
\hline & $\mu_{\mathrm{n}}\left(\mathrm{cm}^{2} \mathrm{~V}^{-1} \mathrm{~s}^{-1}\right)$ & 50 & & & & \\
\hline & $\mu_{\mathrm{p}}\left(\mathrm{cm}^{2} \mathrm{~V}^{-1} \mathrm{~s}^{-1}\right)$ & 50 & & & & \\
\hline & $\varepsilon$ & 30 & & & & \\
\hline & $N_{\mathrm{A}}\left(\mathrm{cm}^{-3}\right)$ & $2.10 \times 10^{17}$ & & & & \\
\hline & $N_{\mathbf{D}}\left(\mathrm{cm}^{-3}\right)$ & 0 & & & & \\
\hline $\mathrm{TiO}_{2}$ & $E_{\mathrm{g}}(\mathrm{eV})$ & 3.26 & & & & \\
\hline
\end{tabular}




\begin{tabular}{llc}
\hline$(90 \mathrm{~nm})$ & $X_{\mathrm{e}}(\mathrm{eV})$ & 4.2 \\
& $N_{\mathrm{C}}\left(\mathrm{cm}^{-3}\right)$ & $1.00 \times 10^{21}$ \\
& $N_{\mathrm{v}}\left(\mathrm{cm}^{-3}\right)$ & $2.00 \times 10^{20}$ \\
& $\mu_{\mathrm{n}}\left(\mathrm{cm}^{2} \mathrm{~V}^{-1} \mathrm{~s}^{-1}\right)$ & $1.00 \times 10^{-3}$ \\
& $\mu_{\mathrm{p}}\left(\mathrm{cm}^{2} \mathrm{~V}^{-1} \mathrm{~s}^{-1}\right)$ & $1.00 \times 10^{-3}$ \\
$\varepsilon$ & 100 \\
$N_{\mathrm{A}}\left(\mathrm{cm}^{-3}\right)$ & $5.00 \times 10^{18}$ \\
$N_{\mathrm{D}}\left(\mathrm{cm}^{-3}\right)$ & $5.00 \times 10^{19}$ \\
\end{tabular}

\section{Results and Discussion}

The results of $P C E$ calculated by varying the HTL material and keeping fixed the ETL and perovskite layers are summarized in Table 2. Recombination in the HTL layer has not been considered, since the simulations show that recombination in this layer does not affect the $P C E$ values. In the case of spiro-OMeTAD, these results agree very well with experimental values extracted from [30]. The last column of Table 2 corresponds to the simulated PCE values assuming that the offset level is zero. This condition is obtained by adjusting the electron affinity for each material.

Table 2. Performance of the solar cell obtained from simulations for each HTL material described in Table 1.

\begin{tabular}{cccc}
\hline $\mathrm{HTL}$ & Offset $(\mathrm{eV})$ & $P C E(\%)$ & $P C E(\%)$ to Offset $=0$ \\
\hline $\mathrm{Cu}_{2} \mathrm{O}$ & 0.06 & 25.06 & 25.10 \\
$\mathrm{CuSCN}$ & 0.13 & 24.86 & 25.11 \\
$\mathrm{NiO}$ & 0.17 & 24.57 & 25.11 \\
$\mathrm{CuI}$ & 0.23 & 23.78 & 25.11 \\
spiro-OMeTAD & 0.32 & 21.79 & 24.37 \\
\hline
\end{tabular}

Data taken from Table 2 are shown in Figure 3, where it can be seen that the PCE decreases when the offset level is increased. 


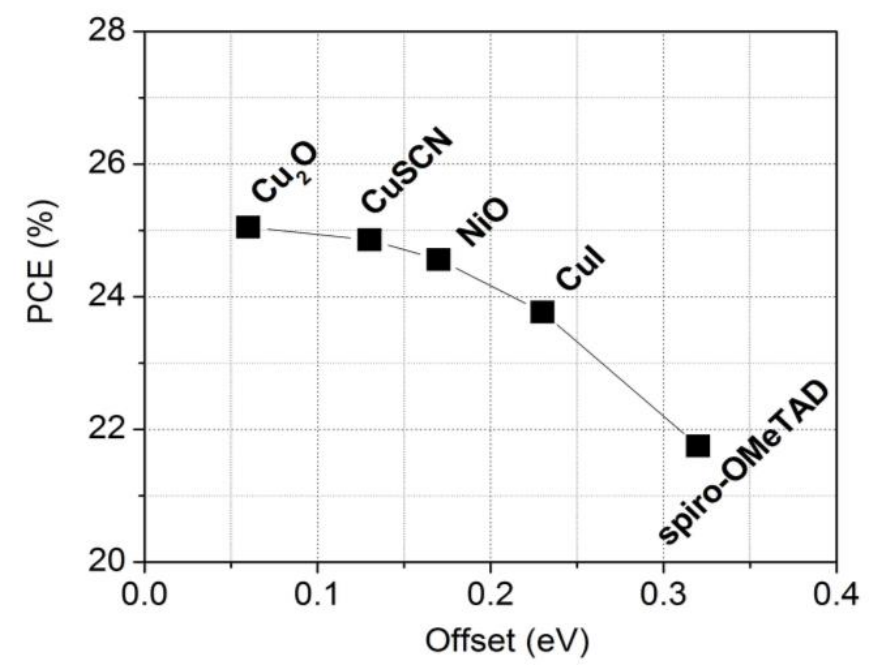

Figure 3. Power conversion efficiency as a function of the offset level between the MVB of the HTL and perovskite layers for the five HTL material considered in this work.

As it can also be observed in Table 2, the minimum value of $P C E$ for the condition offset equal to zero, was found for the spiro-OMeTAD (24.37\%), whereas no differences were found for the rest of the materials evaluated. The reduced performance of the spiro-OMeTAD is due to the low hole mobility in this material $\left(2.00 \times 10^{-4} \mathrm{~cm}^{2} \mathrm{~V}^{-1} \mathrm{~s}^{-1}\right)$. Since the mobility of other materials varies from 2.8 (for $\mathrm{NiO}$ ) to $80 \mathrm{~cm}^{2} \mathrm{~V}^{-1} \mathrm{~s}^{-1}$ (for $\mathrm{Cu}_{2} \mathrm{O}$ ), by almost a factor of 30 , without affecting the $P C E$ value (25.11\%), therefore it is possible to assume that there is a minimum value of mobility above which the change in the $P C E$ is negligible. On the contrary, the $P C E$ is reduced when the mobility values are lower than this minimum value.

In order to fully understand the degradation in the $P C E$ as a function of the hole mobility, new simulations were made for the solar cell with spiro-OMeTAD as hole conductor for the condition offset equal to zero. Specifically, with regard to parameters presented in Table 1, the $\mu_{\mathrm{p}}$ was varied from $2.00 \times 10^{-4}$ to $2.00 \times 10^{-1} \mathrm{~cm}^{2} \mathrm{~V}^{-1} \mathrm{~s}^{-1}$. The other values of Table 1 have remained unchanged. Results obtained are shown in Figure 4(a). Also, the variation of the fill factor $(F F)$ with $\mu_{\mathrm{p}}$ has been studied for the solar cell with spiro-OMeTAD, as can be seen in Figure 4(b). In both cases, in Figure 4(a) and (b), an increase in PCE and FF is observed when the hole mobility is increased. In particular, a value of $P C E$ of $25.11 \%$ has been obtained by $\mu_{\mathrm{p}}=2.00 \times 10^{-1} \mathrm{~cm}^{2} \mathrm{~V}^{-1} \mathrm{~s}^{-1}$. 


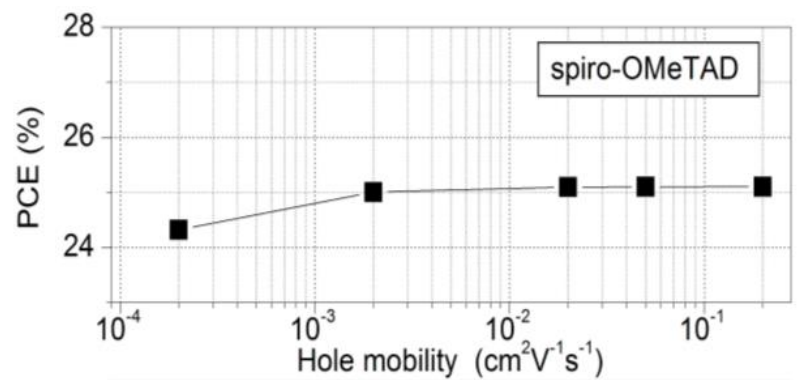

(a)

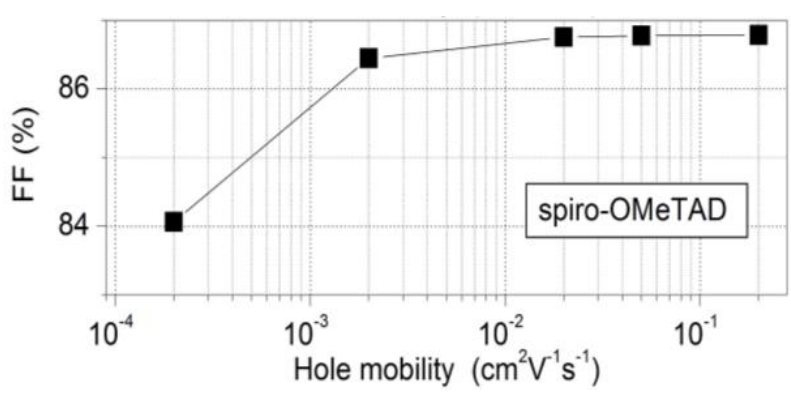

(b)

Figure 4. Power conversion efficiency $(a)$ and fill factor $(b)$ versus hole mobility in the spiro-OMeTAD as Hole Transporting Layer for the condition offset equal to zero.

The $F F$ and $P C E$ can be calculated as [31]:

$$
F F=\left(V_{M P} \cdot I_{M P}\right) /\left(V_{O C} \cdot I_{S C}\right)
$$

and

$$
\operatorname{PCE}(\%)=\left(100 \cdot V_{O C} \cdot I_{S C} \cdot F F / P_{I N}\right)
$$

where $V_{M P}, I_{M P}, V_{O C}$ and $I_{S C}$ represent the voltage at maximum power, the current at maximum power, the open circuit voltage and the short-circuit current, respectively, whereas $P_{I N}$ is the input power from the sun. Since $V_{O C}$ and $I_{S C}$ remain unchanged, it can be concluded that $F F$ is the cause of the increase in $P C E$ when $\mu_{\mathrm{p}}$ is increased.

In order to analyze the behavior of $F F$, in Figure 5 it is plotted the simulated current densityvoltage $(J-V)$ characteristics of the solar cell with spiro-OMeTAD as HTL material for the minimum and maximum values of the hole mobility considered. It is possible to observe in this figure that, for the values of voltage close to $V_{O C}$, the current is lower when $\mu_{\mathrm{p}}$ is decreased. The reason for this drop in the carrier collection at the electrodes can be explained by an 
increase of the recombination rate at voltages close to $V_{O C}$. Therefore, the lower values of $F F$ (and of $P C E$ ) are a consequence of the decrease in the current for the values of voltage close to VOC.

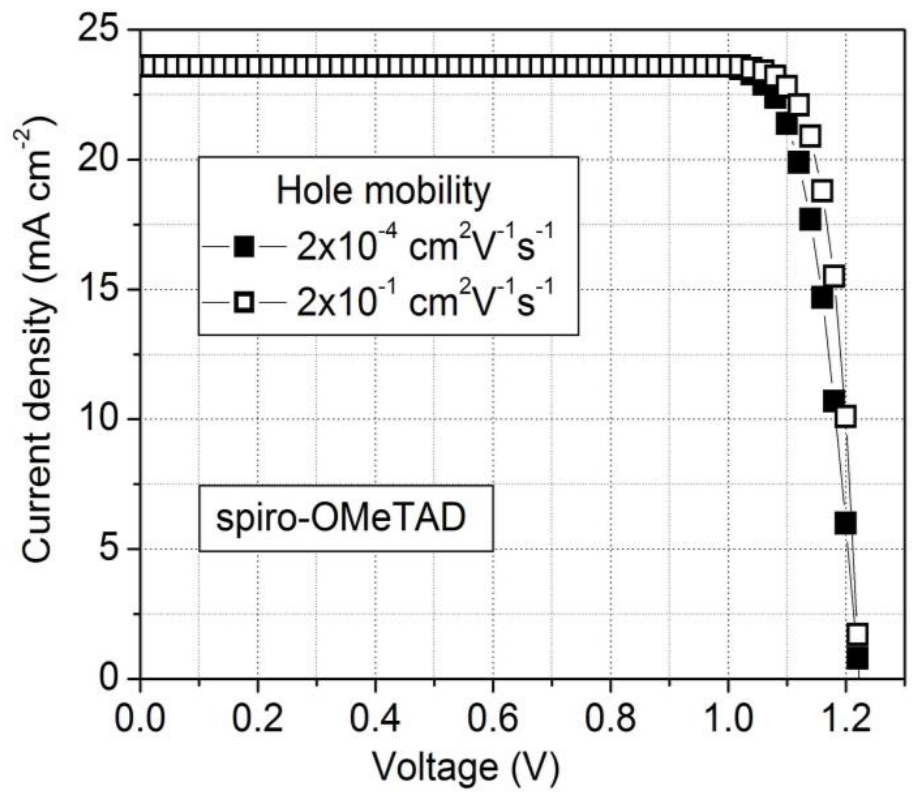

Figure 5. Current density-Voltage curves of the perovskite solar cell for two different hole mobilities in the spiro-OMeTAD layer.

It has been previously mentioned in this work that with four different inorganic materials such as $\mathrm{Cu}_{2} \mathrm{O}, \mathrm{CuSCN}, \mathrm{NiO}$ and $\mathrm{CuI}$, if the electron affinity value is modified in order to remain aligned the MVB of the perovskite and HTL materials (i.e. offset equal to zero), then the performance is the same in all cases. This indicates that for the doping conditions shown in Table 1, the band gap energies and the hole mobilities have no impact on the $P C E$ for these materials.

Since the $\mathrm{Cu}_{2} \mathrm{O}$ is the material with the lowest real offset $(0.06 \mathrm{eV})$, the results obtained on the $\mathrm{Cu}_{2} \mathrm{O} /$ Perovskite $/ \mathrm{TiO}_{2}$ solar cell are analyzed in the rest of the work.

Figure 6 shows data obtained from simulation runs of the electrical parameters degradation ( $V_{O C}, I_{S C}, F F$ and $P C E$ ) as a function of the offset level for the $\mathrm{Cu}_{2} \mathrm{O} /$ Perovskite/TiO ${ }_{2}$ solar cell. The offset level was artificially modified by changing the electron affinity of $\mathrm{Cu}_{2} \mathrm{O}$. The values presented are normalized to those corresponding to the offset level equal to zero, which are 1.22 $\mathrm{V}, 23.64 \mathrm{~mA}, 86.79 \%$ and $25.10 \%$, for $V_{O C}, I_{S C}, F F$ and $P C E$, respectively. The lines through the data points are only intended to guide the eye. Positive offset values indicate that the MVB of the HTL layer is over the MVB of the perovskite layer, such as is the case for the materials considered in this work (Figure 2). Under this condition, according to equation (2), the 
decreasing of $V_{O C}$ is the main reason for the $P C E$ degradation, whereas the fill factor $F F$ is slightly affected by the offset and $I_{S C}$ is remained approximately unchanged. This behavior seems to be contradictory, since the positive offset $\left(M V B_{H T L}-M V B_{\text {Perovskite }}>0\right)$ should involve an electric field that contributes to the flow of holes from perovskite to HTL. In Figure 7 it has been plotted the MVB in the HTL/perovskite interface as a function of the distance $x$ from the front face of the $\mathrm{Cu}_{2} \mathrm{O} /$ Perovskite/TiO${ }_{2}$ solar cell, for two different offsets $(0$ and $0.5 \mathrm{eV}$ ). It is assumed that $x=0$ is the location of the electrode closest to the HTL, and therefore $x=400 \mathrm{~nm}$ is the location of the HTL/perovskite interface. In the case corresponding to an offset level equal to $0.5 \mathrm{eV}$, it can be observed in $x=400 \mathrm{~nm}$ a potential barrier which hinders the motion of holes from perovskite to HTL. Based on the results obtained from simulations, the height of the potential barrier depends not only on the offset, but also on the doping level in both regions and on the voltage ( $0.9 \mathrm{~V}$ in Figure 7). Furthermore, the carrier recombination in the vicinity of $\mathrm{HTL} /$ perovskite interface increases when the height of the potential barrier is greater, which causes lower $V_{O C}, F F$ and $P C E$. The increase of the carrier recombination for an offset level equal to $0.5 \mathrm{eV}$ and the comparison with an offset equal to zero is shown in Figure 8.

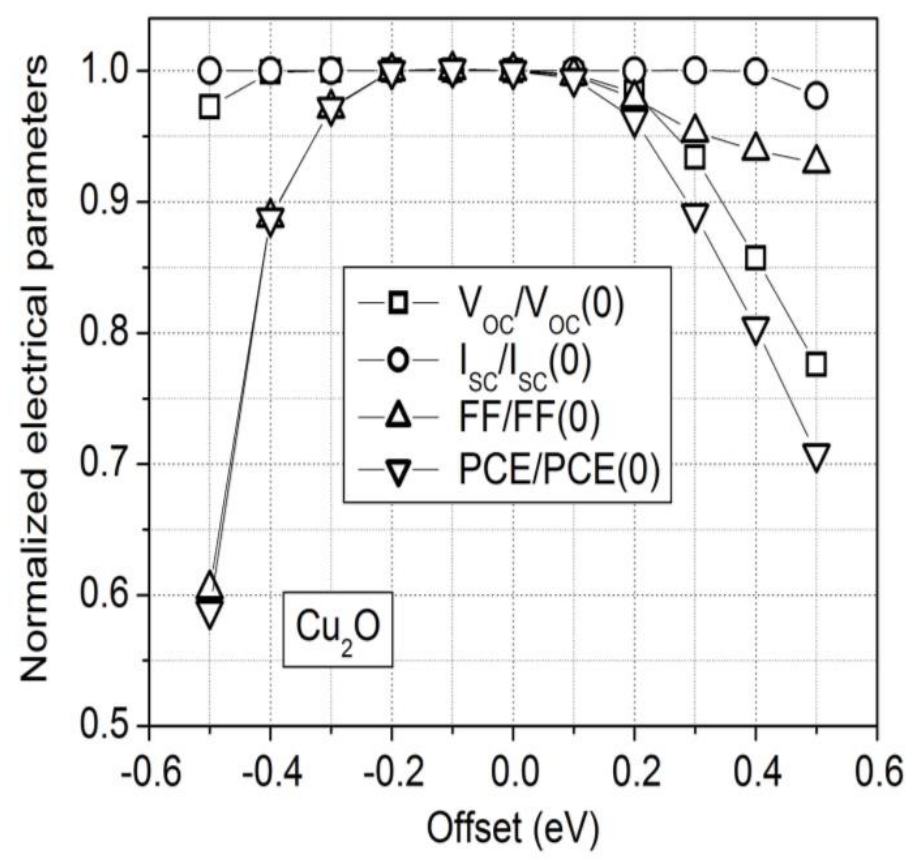

Figure 6. Normalized electrical parameters as a function of the offset level between the MVB of the HTL and perovskite layers for the $\mathrm{Cu}_{2} \mathrm{O} /$ Perovskite/ $/ \mathrm{TiO}_{2}$ solar cell.

On the other hand, in the case of a negative offset $\left(M V B_{H T L}-M V B_{\text {Perovskite }}<0\right)$, the potential barrier makes difficult the extraction of holes generated in the perovskite layer and the $P C E$ decreases rapidly due to the reduction of the $F F$, as can be observed in Figure 6. 


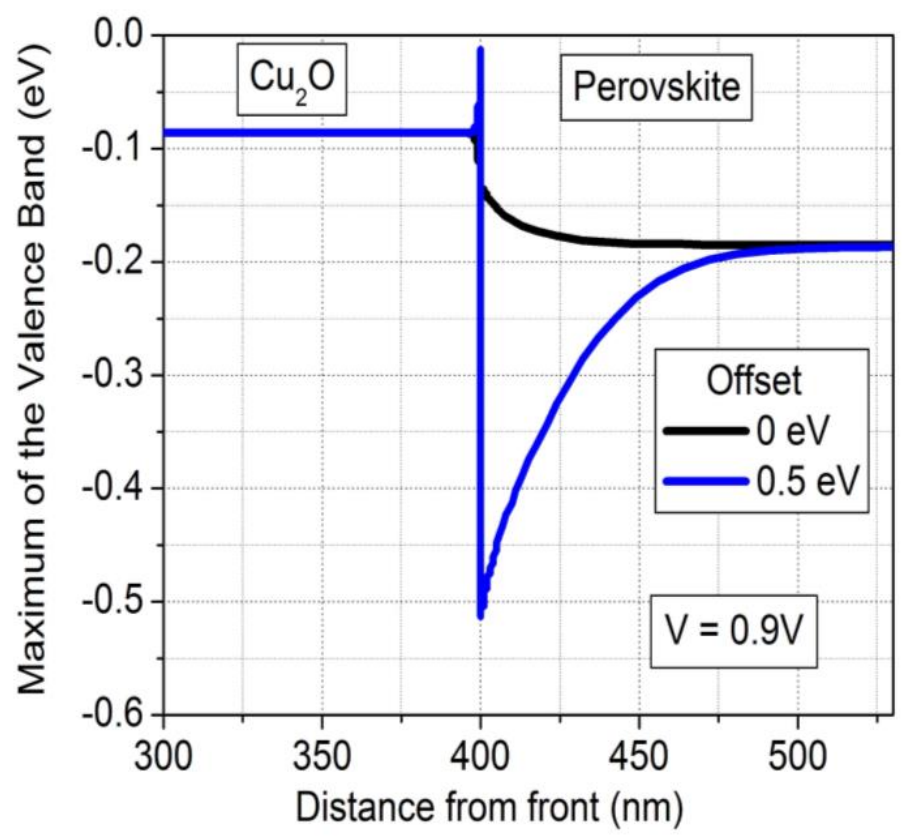

Figure 7. Maximum of the Valence Band as a function of the distance from front in the $\mathrm{HTL} /$ perovskite interface for the $\mathrm{Cu}_{2} \mathrm{O} / \mathrm{Perovskite} / \mathrm{TiO}_{2}$ solar cell. Two different levels of offset have been considered.

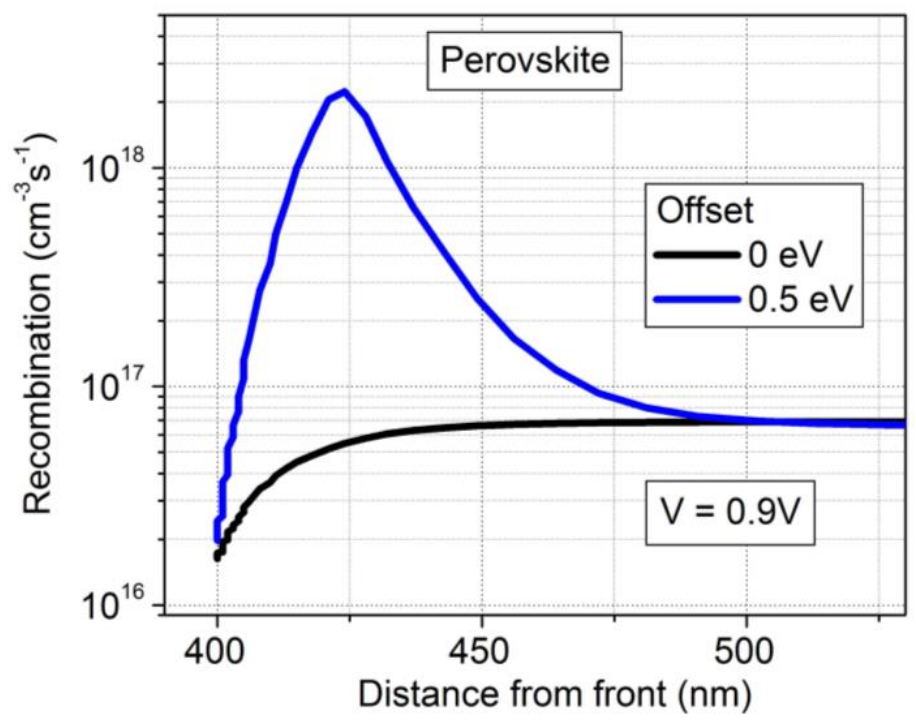

Figure 8. Carrier recombination as a function of the distance from front in the $\mathrm{HTL} /$ perovskite interface for the $\mathrm{Cu}_{2} \mathrm{O} / \mathrm{Perovskite} / \mathrm{TiO}_{2}$ solar cell. Two different levels of offset have been considered.

As it has been mentioned above, based on the simulation results, the height of the potential barrier that causes the increase of the carrier recombination is dependent on the electron affinities and bandgap, which determine the offset level. For a given offset level, the PCE value increases when the acceptor concentration in the perovskite layer $\left(N_{A}\right)$ is larger. Thus, a maximum value of PCE in the order of $28 \%$ has been obtained at $N_{A}=5.00 \times 10^{20} \mathrm{~cm}^{-3}$, for the 
offset equal to zero.

Figure 9 shows the simulated electrical parameters $\left(V_{O C}, I_{S C}, F F\right.$ and $\left.P C E\right)$ as a function of $N_{A}$ in the perovskite layer, for the $\mathrm{Cu}_{2} \mathrm{O} / \mathrm{Perovskite} / \mathrm{TiO}_{2}$ solar cell. The values presented are normalized with respect to the maxima, which are $1.32 \mathrm{~V}, 23.69 \mathrm{~mA}, 89.74 \%$ and $28.07 \%$ for $V_{O C}, I_{S C}, F F$ and $P C E$, respectively. The $P C E$ and $I_{S C}$ values are the most and least increased with $N_{A}$, respectively.

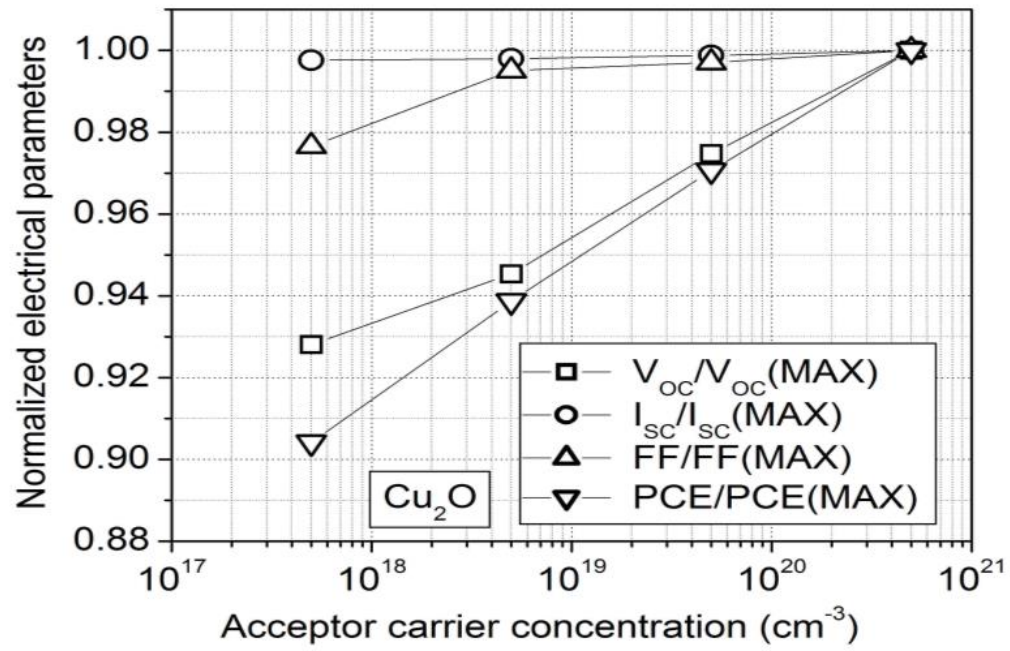

Figure 9. Normalized electrical parameters as a function of the acceptor carrier concentration in the perovskite layer for the $\mathrm{Cu}_{2} \mathrm{O} / \mathrm{Perovskite} / \mathrm{TiO}_{2}$ solar cell.

On the other hand, in the case of the $\mathrm{Cu}_{2} \mathrm{O} / \mathrm{Perovskite} / \mathrm{TiO}_{2}$ solar cell, the acceptor impurities concentration in the HTL layer does not significantly affect the value of PCE. However, low values of hole mobility in the HTL layer (below $3 \mathrm{~cm}^{2} \mathrm{~V}^{-1} \mathrm{~s}^{-1}$ ) reduce the $P C E$ parameter up to $10 \%$ when this region is considered intrinsic $\left(N_{A}=0\right)$ or is slightly doped, as can be seen in Figure 10. From the data presented in Table 1, the hole mobility for spiro-OMeTAD is clearly below $3 \mathrm{~cm}^{2} \mathrm{~V}^{-1} \mathrm{~s}^{-1}$. In opposition, the hole mobilities for $\mathrm{Cu}_{2} \mathrm{O}, \mathrm{CuSCN}$ and $\mathrm{CuI}$ are well above this value, whereas for $\mathrm{NiO}$ is close to $3 \mathrm{~cm}^{2} \mathrm{~V}^{-1} \mathrm{~s}^{-1}$, for which the degradation of the $P C E$ is still negligible. 


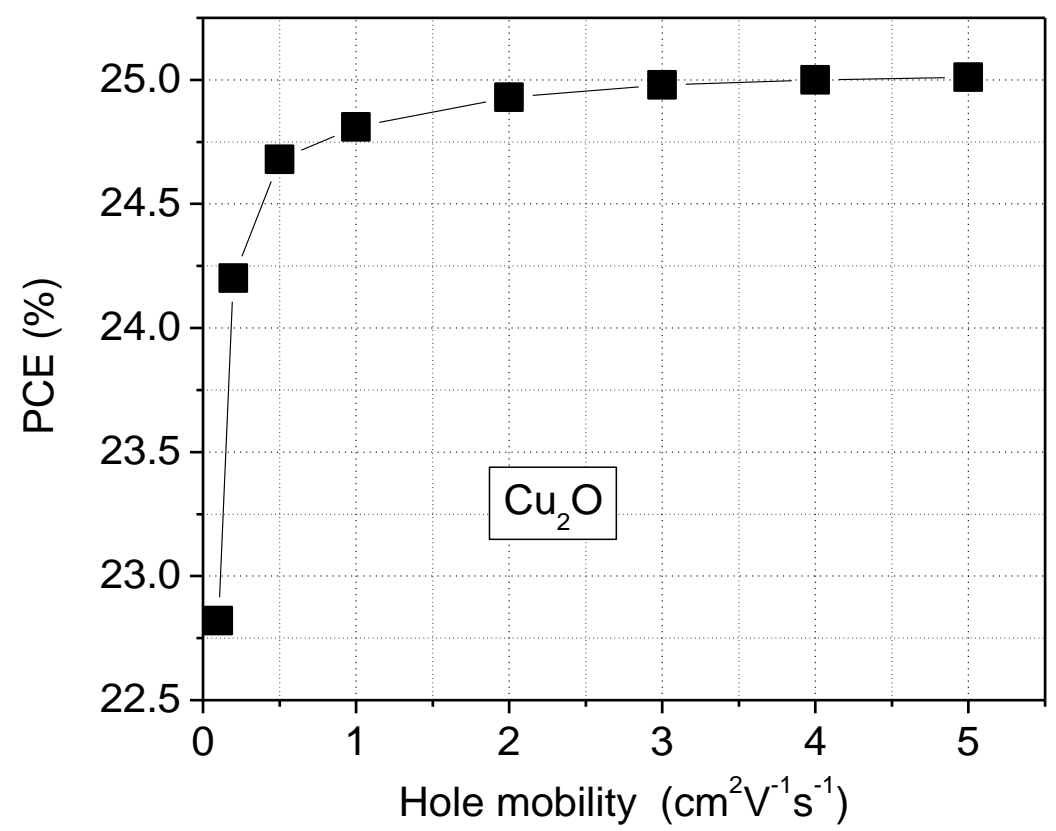

Figure 10. Power conversion efficiency as a function of the hole mobility in the HTL layer for the $\mathrm{Cu}_{2} \mathrm{O} /$ Perovskite/ $\mathrm{TiO}_{2}$ solar cell. The HTL layer is considered intrinsic.

\section{Conclusion}

The behavior of perovskite based solar cells with $\mathrm{p}-\mathrm{p}-\mathrm{n}$ planar structure has been studied through computer simulation using an organic compound (spiro OMeTAD) and four different inorganic materials $\left(\mathrm{Cu}_{2} \mathrm{O}, \mathrm{CuSCN}, \mathrm{NiO}\right.$ and $\left.\mathrm{CuI}\right)$ as Hole Transporting Layer (HTL). The results obtained in this work show that the performance of these devices can be still improved with respect to the prototypes reported in the literature, which have efficiencies in the order of $20 \%$ when the HTL layer is the organic spiro OMeTAD. However, so far, experimental results of efficiency of inorganic hole conductor-based perovskite solar cells is still much lower than that of the traditional organic hole conductor-based cells. This can be mainly due to the fact that both, the qualities of the manufacturing processes and HTL layer, and the amount of defects in the HTL/perovskite interface, have a big influence in the performance of perovskite devices. Data obtained from simulation runs also show that the most decisive effect on the $P C E$ is the potential barrier in the HTL/perovskite interface. The alignment between the Maximum of the Valence Band (MVB) of the HTL and perovskite materials (which is directly related to the band gap energy and the electron affinity of each material), is a key factor to reduce the height of the potential barrier. The other major factor involved is the doping level in p-type perovskite layer. For the maximum value of $N_{A}$ in the perovskite region considered in this work $\left(5.00 \times 10^{20} \mathrm{~cm}^{-3}\right)$, efficiency in the order of $28 \%$ has been obtained for the $\mathrm{Cu}_{2} \mathrm{O} /$ Perovskite/TiO 2 solar cell for the condition offset equal to zero. The hole mobilities in the HTL play a fundamental role up to a certain minimum value (close to $3 \mathrm{~cm}^{2} \mathrm{~V}^{-1} \mathrm{~s}^{-1}$ ), below which the $P C E$ is reduced. The hole mobilities for $\mathrm{Cu}_{2} \mathrm{O}, \mathrm{CuSCN}$ and 
$\mathrm{CuI}$ are well above the minimum value, for $\mathrm{NiO}$ coincides with this value, whereas for spiroOMeTAD is clearly below the minimum value. Since the most common material used nowadays for the HTL layer is spiro-OMeTAD, results obtained in this work show that this material can be replaced to improve the efficiency.

\section{References}

[1] M. Green, et al., The Emergence of Perovskite Solar Cells, Nature Photonics 8 (2014) 506-514.

[2] C. Zuo et al., Advances in Perovskite Solar Cells, Advanced Science (2016) 1500324 (16pp).

[3] A. Kojima, K. Teshima, Y. Shirai, T. Miyasaka, Organometal halide perovskites as visible-light sensitizers for photovoltaic cells, Journal of the American Chemical Society 131 (2009) 6050-6051.

[4] National Renewable Energy Laboratory (NREL) Efficiency Chart.

http://www.nrel.gov/pv/assets/images/efficiency_chart.jpg (Rev. February 12, 2016).

[5] M. Javad Taghavi et al., Modeling of optical losses in perovskite solar cells, Superlattices and Microstructures 97 (2016) 424-428.

[6] F. Liu et al., Numerical simulation: Toward the design of high-efficiency planar perovskite solar cells, Applied Physics Letters 104 (2014) 253508 (4pp).

[7] L. Peng et al., Device simulation of solid-state perovskite solar cells, 31st European Photovoltaic Solar Energy Conference and Exhibition (2015).

[8] Y. Zhou, A. Gray-Weale, A numerical model for charge transport and energy conversion of perovskite solar cells, Phys. Chem. Chem. Phys., 18 (2016) 4476-4486.

[9] A. Baktash, O. Amiri, A. Sasani, Improve efficiency of perovskite solar cells by using Magnesium doped ZnO and $\mathrm{TiO} 2$ compact layers, Superlattices and Microstructures 93 (2016) 128-137.

[10] K. Adhikari, S. Gurung, B. Bhattarai, B. Soucase, Comparative study on MAPbI3 based solar cells using different electron transporting materials, Phys. Status Solidi C (2015) 1-5.

[11] S. Chatterjee, A. Pal, Introducing $\mathrm{Cu} 2 \mathrm{O}$ thin films as a Hole-Transport Layer in efficient planar perovskite solar cell structures, J. Phys. Chem. C 120 (2016) 1428-1437.

[12] S. Ye et al., CuSCN-based inverted planar perovskite solar cell with an average PCE of 15.6, Nano Lett. 15 (2015) 3723-3728.

[13] M. Cappelletti et al., Study of the electrical parameters degradation of GaAs sub-cells for triple junction space solar cells by computer simulation, Semiconductor Science and Technology, 31 (2016) 115020.

[14] M. Cappelletti et al., Theoretical study of the maximum power point of n-type and p-type crystalline silicon space solar cells, Semiconductor Science and Technology, 28 (2013) 045010.

[15] A. Cédola et al., An Iterative Method Applied to Optimize the Design of PIN Photodiodes for Enhanced Radiation Tolerance and Maximum Light Response, Nuclear Instruments and Methods in Physics Research, Section A, 629 (2011) 392-395.

[16] M. Burgelman et al., Modelling polycrystalline semiconductor solar cells, Thin Solid Films 361 (2000) 527-532.

[17] D. Stranks et al., Electron-Hole diffusion lengths exceeding 1 micrometer in an organometal trihalide perovskite absorber, Science 342 (2013) 341-345.

[18] J. Noh et al., Chemical management for colorful, efficient, and stable inorganic-organic hybrid nanostructured solar cells, Nano Letters 13 (2013) 1764-1769.

[19] H. Snaith, M. Gratzel, Electron and Hole Transport through mesoporous TiO2 infiltrated with Spiro-MeOTAD, Adv. Mater. 19 (2007) 3643-3647.

[20] M. Lee et al., Efficient hybrid solar cells based on meso-superstructured organometal halide perovskites, Science 338 (2102) 643-647.

[21] M. Hirasawa et al., Magnetoabsorption of the lowest exciton in perovskite-type compound $\left(\mathrm{CH}_{3} \mathrm{NH}_{3}\right) \mathrm{PbI}_{3}$, Physica B: Physics of Condensed Matter, 201 (1994) 427-430.

[22] W. Sekkal, A. Zaoui, Monte Carlo study of transport properties in copper halides, Physica B: Physics of Condensed Matter 315 (2002) 201-209.

[23] P. Sirimanne et al., Characterization of transparent conducting CuI thin films prepared by pulse laser deposition technique, Chemical Physics Letters 366 (2002) 485-489.

[24] F. Biccari, Defects and doping in Cu2O, PhD Thesis, Roma, Italy, 2009.

[25] Q. Deng, X. Han, T. Gao, G. Shao, Remarkable optical red shift and extremely high optical absorption coefficient of V-Ga co-doped TiO2, J. Appl. Phys 112 (2012) 013523 (8pp).

[26] D. Poplavskyy, J. Nelson, Nondispersive hole transport in amorphous films of methoxy-spirofluorene-arylamine organic compound, J. Appl. Phys. 93 (2003) 341-346.

[27] C. Malerba et al., Absorption coefficient of bulk and thin film Cu2O, Solar Energy Materials \& Solar Cells 95 (2011) 2848-2854.

[28] P. Ahirrao et al., Wide band gap nanocrystalline CuSCN thin films deposited by modified chemical method, Archives of Physics Reserchs. Scholars Reserchs Library 2 (2011) 29-33.

[29] S. Sriram, A. Thayumanavan, Structural, optical and electrical properties of NiO thin films prepared by low cost spray pyrolysis technique, Internat. Journal of Materials Science and Engineering 1 (2013) 118-121.

[30] M. Green, K. Emery, Y. Hishikawa, W. Warta, E. Dunlop, Solar cell efficiency tables (version 47), Progress in Photovoltaics: Research and Appl. 24 (2016) 3-11. 
[31] S. Sze, K. Ng, Physics of Semiconductor Devices. 3rd edn, John Wiley \& Sons., Hoboken, New Jersey, 2007.

Funding: This work was partially supported by the Universidad Nacional de Quilmes, Argentina, by the Universidad Nacional Arturo Jauretche, Argentina, by the Universidad Nacional de La Plata, Argentina, by the National Council Research (CONICET), Argentina, and by the Ministerio de Economía y Competitividad (Grant ENE2016-77798-C4-2-R), Spain. 